\title{
The cost-effectiveness of lipid lowering in patients with diabetes: results from the $\mathbf{4 S}$ trial
}

\author{
B. Jönsson ${ }^{1}$, J. R. $\operatorname{Cook}^{2}$, T. R. Pedersen ${ }^{3}$ \\ ${ }^{1}$ Stockholm School of Economics, Stockholm, Sweden \\ ${ }^{2}$ Merck Research Laboratories, Blue Bell, Pennsylvania, USA \\ ${ }^{3}$ Aker Hospital, Oslo, Norway
}

\section{Abstract}

Aims/hypothesis. The purpose of this study is to investigate the cost-effectiveness of simvastatin in diabetic patients, using prospectively collected outcomes data from the Scandinavian Simvastatin Survival Study.

Methods. Diabetic patients were identified using two different classifications schemes: Clinical history (diabetic, non-diabetic) and the new American Diabetes Association definition (diabetic, impaired fasting glucose, normal fasting glucose). The analysis is based on prospectively collected data from the trial on hospitalization for cardiovascular problems, study drug utilization and mortality. The incremental cost per life year saved with simvastatin is estimated using costs from Sweden (primary) and other European countries.

Results. Hospitalizations for cardiovascular problems were considerably reduced with simvastatin therapy, with the greatest differences in the diabetic subgroups. Reductions in hospitalizations in the diabetic group resulted in substantial hospital cost savings that offset 67 to $76 \%$ of the drug cost (depending on the classification used). For the diabetic patients, the estimates of the cost per life-year gained ranged from 1600 Euros (based on clinical history) to 3200 Euros (based on American Diabetes Association) using Swedish costs. In the other evaluated European countries treatment with simvastatin showed a favourable cost-effectiveness ratio independent of differences in local health care unit costs.

Conclusion/interpretation. For all subgroups in the diabetic classification schemes, treatment with simvastatin resulted in estimates of cost per life-year gained that were well within the range generally considered to be cost effective. Based on the Scandinavian Simvastatin Survival Study, simvastatin therapy provides good value for money in both diabetic and non-diabetic patients with cardiovascular disease. [Diabetologia (1999) 42: 1293-1301]

Keywords Scandinavian Simvastatin Survival Study (4S), cost-effectiveness, cholesterol, lipid lowering.
Received: 18 February 1999 and in final revised form: 1 July 1999

Corresponding author: B. Jönsson, Stockholm School of Economics, Sveavagen 65, Box 6501, S-113 83 Stockholm, Sweden Abbreviations: 4S, Scandinavian Simvastatin Survival Study; ADA, American Diabetes Association; CHD, coronary heart disease; DRG, diagnosis-related group; FG, fasting glucose; IFG, impaired fasting glucose; MI, myocardial infarction; NFG, non-fasting glucose; ECU, Euro; PTCA, percutaneous transluminal coronary angioplasty; $\mathrm{CABG}$, coronary artery bypass graft; SEK, Swedish Crown.
Diabetes is a major source of morbidity, mortality and medical costs. It has been estimated that nearly $15 \%$ of national health care expenditures in the USA is spent on treating patients with diabetes [1]. Patients with diabetes have about three-to-fourfold higher health care costs than patients without diabetes, and Type II (non-insulin-dependent) diabetes accounts for over $90 \%$ of patients with diabetes and the overwhelming part of the costs [2-5]. If the value of productivity lost, due to disability and premature death, is added to the cost of health care, the cost of diabetes is doubled. An important part of the costs due to diabetes results from complications of the dis- 
ease. Estimates for Sweden show that these complications account for three-quarters of the cost of diabetes, and that this share has been constant over the last decades [6, 7].

Cardiovascular disease accounts for the main part of the cost of chronic complications. In the USA, cardiovascular disease accounts for two-thirds of the cost of long-term complications of diabetes and two-thirds of all deaths attributed to diabetes [5]. Prevention of cardiovascular complications due to diabetes thus have the potential to both reduce health care costs and to improve survival.

The risk of cardiovascular disease is substantially higher in diabetic patients compared with non-diabetic patients [8]. Among subjects who have survived a myocardial infarction (MI), patients with diabetes have an increased risk of mortality and re-infarction compared with non-diabetic patients [9]. The increased coronary risk in diabetic patients is in part explained by adverse effects of diabetes on lipid concentrations and other cardiovascular risk factors. Thus, interventions aimed at improving the risk factor profile possibly have a greater relative impact on mortality and morbidity among diabetic patients with a previous MI or angina or both than among non-diabetic patients [10].

Clinical results from the diabetic subgroup in the Scandinavian Simvastatin Survival Study (4S) based on clinical history have been published previously, showing a $55 \%$ reduction in the risk of coronary death and non-fatal MIs in patients treated with simvastatin [10]. In 1997, a new classification scheme for diabetic patients was developed by the American Diabetes Association (ADA). In the new scheme, a patient is classified as diabetic if the fasting glucose (FG) is equal or greater than $7.0 \mathrm{mmol} / \mathrm{l}$ or if the patient is classified as diabetic based on clinical history. Patients with FG between $6.0-7.0 \mathrm{mmol} / 1$ are classified as having impaired fasting glucose (IFG), while those with FG below $6.0 \mathrm{mmol} / \mathrm{l}$ are classified as having normal fasting glucose (NFG). Using this scheme to classify patients in $4 \mathrm{~S}$ showed substantial and considerable benefit of simvastatin treatment to both diabetic and patients with IFG on coronary heart disease (CHD) events and revascularization. In addition, significant decreases in mortality and severe coronary events were observed in subjects with IFG who were treated with simvastatin [11].

The purpose of this study was to investigate the cost-effectiveness of cholesterol lowering with simvastatin in diabetic patients with coronary disease, using data from the $4 \mathrm{~S}$. This study collected outcome data necessary for an economic evaluation and previous analyses evaluating the entire cohort and subgroups defined by age, sex and baseline cholesterol have been published [12-14]. Our analysis evaluated the impact of simvastatin on resource consumption and cost-effectiveness in diabetic patients using clinical history and the ADA criterion.

\section{Subjects and methods}

The Scandinavian Simvastatin Survival Study (4S) was a double-blind, randomized and placebo controlled study, carried out at 94 centres in the "five Nordic countries" Denmark, Finland, Iceland, Norway and Sweden. The study included 4444 men and women aged 35-70 years with a prior MI or angina or both. Patients were randomized to treatment with simvastatin 20 to $40 \mathrm{mg}$ or placebo, and the drug was titrated to reach a total cholesterol concentration of $5 \mathrm{mmol} / \mathrm{l}$. Total cholesterol at baseline ranged $5.5-8.0 \mathrm{mmol} / \mathrm{l}$ and the median follow up time was 5.4 years. The primary endpoint was all-cause mortality and the secondary endpoints were death from CHD and non-fatal MI.

Diabetic patients were identified using two different classification schemes: based on clinical history alone and in combination with the ADA criterion. Using the criteria in place when the study was designed, 202 of the 4444 patients $(4.5 \%)$ were originally classified as diabetic by the investigator based on clinical history. Of the 202 diabetic patients, $12 \%$ were treated with insulin, 39\% with oral hypoglycaemic drugs and $50 \%$ with diet only. A second classification scheme was based on the ADA definition. Fasting blood glucose concentrations were available at randomization for 4398 of the 4444 patients in $4 \mathrm{~S} .483$ patients $(11 \%)$ were classified as diabetic based on either clinical history or FG concentrations of at least $7.0 \mathrm{mmol} / \mathrm{l}$. For 678 patients $\mathrm{FG}$ was greater than $6.0 \mathrm{mmol} / \mathrm{l}$, but less than $7.0 \mathrm{mmol} / \mathrm{l}$, and these were classified as IFG. The remaining 3237 patients were classified as NFG. A description of the patients according to the two classification schemes is in Table 1.

For subgroups defined with both classification schemes, the number of life-years gained was calculated as the difference in the mean estimated remaining life expectancy between patients randomized to treatment with simvastatin or placebo. For each treatment, the mean survival time during the first 5.5 years of the trial was estimated by the area under the Kaplan Meier survival curve. Life expectancy beyond 5.5 years was based on the estimated Kaplan Meier survival probability at 5.5 years and an average remaining life expectancy for the survivors (assumed to be independent of treatment). Based on actuarial data an average life expectancy of 10 additional years is assumed for NFG patients who survived after 5.5 years of the trial [15]. A number of studies have shown the relative risk of mortality in coronary patients is roughly twice as great for patients with diabetes vs those without diabetes [8, 9, 16-18]. Based on these data, 5 additional years were assumed for diabetic patients who survived to the end of the trial. Patients with IFG were assumed to survive 7.5 additional years. These assumptions were varied in sensitivity analyses to determine their impact on the overall results. For discounting purposes only, mortality beyond 5.5 years was assumed to occur at a constant rate.

Data on hospitalizations for cardiovascular problems and simvastatin dosage were collected prospectively in $4 \mathrm{~S}$, and were used to derive the average cost per patient during the trial. The number and rate of hospitalizations per 1000 patients were estimated for patients randomized to treatment with simvastatin or placebo according to diabetic status. Confidence intervals for the difference in the rate of hospitalizations per 1000 patients were computed using the empirical limits of 1000 bootstrap re-samples for each subgroup [19]. The costs 
Table 1. Baseline patient demographics among subgroups defined according to clinical history and ADA criteria for diabetes

\begin{tabular}{|c|c|c|c|c|c|c|c|c|c|c|}
\hline \multirow[t]{2}{*}{ Demographic characteristic } & \multicolumn{4}{|c|}{ Clinical History } & \multicolumn{6}{|c|}{ ADA Criteria } \\
\hline & \multicolumn{2}{|c|}{$\begin{array}{l}\text { Non-diabetic } \\
(n=4242)\end{array}$} & \multicolumn{2}{|c|}{$\begin{array}{l}\text { Diabetic } \\
(n=202)\end{array}$} & \multicolumn{2}{|c|}{$\begin{array}{l}\text { NFG } \\
(n=3237)\end{array}$} & \multicolumn{2}{|c|}{$\begin{array}{l}\text { IFG } \\
(n=678)\end{array}$} & \multicolumn{2}{|c|}{$\begin{array}{l}\text { Diabetic } \\
(n=483)\end{array}$} \\
\hline Age & 58.6 & 7.1 & 59.9 & 6.6 & 58.5 & 7.1 & 58.7 & 7.2 & 59.3 & 6.8 \\
\hline Body Mass Index $\left(\mathrm{kg} / \mathrm{m}^{2}\right)$ & 25.9 & 3.3 & 27.2 & 3.6 & 25.7 & 3.2 & 26.3 & 3.4 & 27.0 & 3.7 \\
\hline $\begin{array}{l}\text { Total Cholesterol }(\mathrm{mmol} / \mathrm{l}) \\
\text { Triglycerides }(\mathrm{mmol} / \mathrm{l}) \\
\text { HDL (mmol/l) } \\
\text { LDL }(\mathrm{mmol} / \mathrm{l})\end{array}$ & $\begin{array}{l}6.75 \\
1.49 \\
1.19 \\
4.88\end{array}$ & $\begin{array}{l}0.66 \\
0.50 \\
0.30 \\
0.66\end{array}$ & $\begin{array}{l}6.71 \\
1.73 \\
1.13 \\
4.80\end{array}$ & $\begin{array}{l}0.67 \\
0.65 \\
0.25 \\
0.67\end{array}$ & $\begin{array}{l}6.74 \\
1.47 \\
1.20 \\
4.88\end{array}$ & $\begin{array}{l}0.66 \\
0.48 \\
0.30 \\
0.66\end{array}$ & $\begin{array}{l}6.75 \\
1.55 \\
1.17 \\
4.88\end{array}$ & $\begin{array}{l}0.68 \\
0.52 \\
0.29 \\
0.66\end{array}$ & $\begin{array}{l}6.74 \\
1.66 \\
1.13 \\
4.85\end{array}$ & $\begin{array}{l}0.68 \\
0.58 \\
0.29 \\
0.67\end{array}$ \\
\hline Sex: \% Male & \multicolumn{2}{|c|}{82} & \multicolumn{2}{|r|}{78} & \multicolumn{2}{|c|}{80} & \multicolumn{2}{|r|}{84} & \multicolumn{2}{|r|}{84} \\
\hline $\begin{array}{l}\text { Qualifying diagnosis \% } \\
\text { Angina only } \\
\text { MI only } \\
\text { Both }\end{array}$ & & $\begin{array}{l}1 \\
3 \\
7\end{array}$ & & $\begin{array}{l}20 \\
63 \\
17\end{array}$ & & $\begin{array}{l}22 \\
61 \\
17\end{array}$ & & $\begin{array}{l}18 \\
66 \\
16\end{array}$ & & $\begin{array}{l}16 \\
69 \\
16\end{array}$ \\
\hline
\end{tabular}

for hospitalizations were calculated by classifying hospitalizations according to the diagnosis-related group (DRG) system. The estimated total cost for hospitalizations was obtained for each patient by summing the costs of all hospitalizations, based on the relevant DRG weight for each hospitalization.

The cost of simvastatin was based on the daily dosage prescribed during the follow-up period. For each patient randomized to treatment with simvastatin, the daily cost was calculated and accumulated over the time the patient was in the trial. The total cost for patients randomized to treatment with simvastatin was taken as the sum of the costs for hospitalizations and simvastatin therapy. The per cent offset in the cost of study medication due to reductions in the cost of hospitalizations was estimated based on the average cost of simvastatin per patient and the difference in the average per patient cost for hospitalizations. The net cost for patients randomized to treatment with simvastatin was also estimated and $95 \%$ confidence intervals were obtained using the bootstrap method.

The base case analysis was undertaken using costs for Sweden, the country that contributed most of the patients to the trial. Additional analyses were done with hospitalization and drug costs from 10 other European countries to determine the impact of local drug and hospitalization costs on the overall results. (The unit costs for each country evaluated in these analyses are available from the authors.) The most recently available unit cost data were used (ranging from 1995 to 1997, depending upon the country, for DRG weights). Due to the lack of a relevant price index for DRGs and the low general inflation, no attempt was made to correct for potential price changes over time.

Cost-effectiveness is a form of economic evaluation of health care programmes where cost is related to a measure of outcome in terms of physical units such as "years of life gained".

The method used to calculate the cost-effectiveness ratio is the same as described in a previous cost-effectiveness study of all patients in the $4 \mathrm{~S}$ study [12]. The cost of the intervention, simvastatin, minus savings from a reduction in the costs of hospitalizations for $\mathrm{CHD}$, is related to the number of life years gained from the reduction in mortality. Costs in added years of life are not considered in order to allow comparison with previous and other studies [20]. The intervention is defined as cost-effective if the cost-effectiveness ratio, the cost per life year gained, is below a threshold value of 200000 SEK (22000ECU) [13].

Cost-effectiveness ratios were estimated as the ratio of the incremental cost to the gain in life years for patients randomized to treatment with simvastatin compared with placebo. Scatterplots of the incremental cost vs incremental life years gained were made based on 1000 bootstrap re-samples for each subgroup. For each bootstrap replicate the cost-effectiveness ratio was computed. For each subgroup, a $95 \%$ confidence interval for the ratio was constructed using the empirical limits of 1000 bootstrap re-samples [21]. (By taking into account the sign of the numerator and denominator in the bootstrap re-samples of the incremental cost-effectiveness ratio, this method essentially resulted in an interval that contained $47.5 \%$ of the points that lie in a counter-clockwise rotation from the full sample estimate and $47.5 \%$ of the points that lie in a clockwise rotation.) The probability that the cost-effectiveness ratio would fall below 100000 Swedish Krona (SEK), 150000 SEK and 200000 SEK per life year saved was also estimated using the bootstrap replicates. A 3\% annual discount rate was applied to future costs and benefits.

\section{Results}

The survival probability at 5.5 years was estimated for patients randomized to receive simvastatin or placebo according to the two diabetes classification approaches (Table 2). Simvastatin increased the survival probability in all subgroups. Based on the $95 \%$ confidence interval for the difference in survival at 5.5 years, the estimated gains (Table 2 ) with simvastatin were significant $(p<0.05)$ except for the diabetic subgroup based on the ADA criteria (where the $95 \%$ confidence interval for the difference contains zero). The IFG patients who received placebo had a survi- 
Table 2. Kaplan-Meier survival estimates at 5.5 years among subgroups defined according to clinical history and ADA criteria for diabetes

\begin{tabular}{|c|c|c|c|c|c|c|}
\hline & \multicolumn{2}{|l|}{ Simvastatin } & \multicolumn{2}{|l|}{ Placebo } & \multicolumn{2}{|c|}{ Difference (Simvastatin - Placebo) } \\
\hline & $\begin{array}{l}\text { Survival } \\
\text { probability }\end{array}$ & $95 \% \mathrm{CI}$ & $\begin{array}{l}\text { Survival } \\
\text { probability }\end{array}$ & $95 \% \mathrm{CI}$ & $\begin{array}{l}\text { Survival } \\
\text { probability }\end{array}$ & $95 \% \mathrm{CI}$ \\
\hline $\begin{array}{l}\text { ADA Criteria } \\
\text { NFG } \\
\text { IFG } \\
\text { Diabetic }\end{array}$ & $\begin{array}{l}0.9197 \\
0.9278 \\
0.8765\end{array}$ & $\begin{array}{c}(0.9056,0.9338) \\
(0.8996,0.9560) \\
(0.8357,0.9173)\end{array}$ & $\begin{array}{l}0.8955 \\
0.8746 \\
0.8309\end{array}$ & $\begin{array}{c}(0.8803,0.9107) \\
(0.8391,0.9101) \\
(0.7803,0.8815)\end{array}$ & $\begin{array}{l}0.0242 \\
0.0532 \\
0.0456\end{array}$ & $\begin{array}{l}(0.0035,0.0449) \\
(0.0079,0.0985) \\
(-0.0194,0.1106)\end{array}$ \\
\hline
\end{tabular}

Table 3. Projected survival time with $95 \%$ Bootstrap CI for treatment difference among subgroups defined according to clinical history and ADA criteria for diabetes (base case and sensitivity analysis for assumed life expectancy for patient surviving to 5.5 years of trial)

\begin{tabular}{|c|c|c|c|c|c|c|c|c|c|}
\hline & \multirow{2}{*}{$\begin{array}{l}\text { Assumed } \\
\text { LE post } 5.5 \\
\text { Year }\end{array}$} & \multicolumn{4}{|c|}{ Undiscounted } & \multicolumn{4}{|c|}{ Discounted (3\%) } \\
\hline & & Simvastatin & Placebo & Difference & $95 \% \mathrm{CI}$ & Simvastatin & Placebo & Difference & $95 \% \mathrm{CI}$ \\
\hline \multicolumn{10}{|l|}{$\begin{array}{l}\text { A. Base Case } \\
\text { Clinical History }\end{array}$} \\
\hline Non-diabetic & 10 & 14.472 & 14.132 & 0.341 & $(0.116 ; 0.578)$ & 11.524 & 11.268 & 0.256 & $(0.089 ; 0.437)$ \\
\hline Diabetic & 5 & 9.483 & 8.855 & 0.628 & $(-0.228 ; 1.406)$ & 8.226 & 7.738 & 0.488 & $(-0.221 ; 1.116)$ \\
\hline $\begin{array}{l}\text { ADA Criteria } \\
\text { NFG } \\
\text { IFG } \\
\text { Diabetic }\end{array}$ & $\begin{array}{l}10 \\
7.5 \\
5\end{array}$ & $\begin{array}{r}14.491 \\
12.269 \\
9.547\end{array}$ & $\begin{array}{r}14.188 \\
11.757 \\
9.327\end{array}$ & $\begin{array}{l}0.303 \\
0.513 \\
0.220\end{array}$ & $\begin{array}{l}(0.056 ; 0.569) \\
(0.066 ; 0.974) \\
(-0.249 ; 0.695)\end{array}$ & $\begin{array}{r}11.538 \\
10.184 \\
8.279\end{array}$ & $\begin{array}{r}11.310 \\
9.783 \\
8.109\end{array}$ & $\begin{array}{l}0.228 \\
0.401 \\
0.170\end{array}$ & $\begin{array}{l}(0.043 ; 0.428) \\
(0.046 ; 0.767) \\
(-0.219 ; 0.562)\end{array}$ \\
\hline \multicolumn{10}{|c|}{$\begin{array}{l}\text { B. Sensitivity Analysis } \\
\text { Clinical History }\end{array}$} \\
\hline $\begin{array}{l}\text { Non-diabetic } \\
\text { Diabetic }\end{array}$ & $\begin{array}{r}14 \\
8\end{array}$ & $\begin{array}{l}18.146 \\
12.083\end{array}$ & $\begin{array}{l}17.696 \\
11.084\end{array}$ & $\begin{array}{l}0.450 \\
0.999\end{array}$ & $\begin{array}{l}(0.150 ; 0.764) \\
(-0.221 ; 2.138)\end{array}$ & $\begin{array}{r}13.530 \\
9.970\end{array}$ & $\begin{array}{r}13.214 \\
9.233\end{array}$ & $\begin{array}{l}0.316 \\
0.737\end{array}$ & $\begin{array}{l}(0.107 ; 0.537) \\
(-0.206 ; 1.612)\end{array}$ \\
\hline
\end{tabular}

val probability between that of the NFG and the diabetic patients. Among those who received simvastatin, however, the IFG patients had the highest survival probability. Consequently, the gains from therapy were the largest for the IFG subgroup although confidence intervals for the treatment effect overlapped across the three subgroups defined by the ADA guidelines.

The projected survival time was based on the Kaplan-Meier mean follow-up to 5.5 years during trial and projected life expectancy beyond the trial for those surviving to 5.5 years (Table 3 ). For all subgroups, patients treated with simvastatin had a longer projected survival time than patients who received placebo. A similar survival time was projected for diabetic patients treated with simvastatin with the two classification schemes. For patients receiving placebo, a longer survival time was projected for the diabetic patients defined by ADA. Consequently, the gain in survival with simvastatin was greater for the diabetic patients defined by clinical history. With the
ADA classification, simvastatin yielded the greatest gains in survival time among the IFG group. Because of the higher survival probability at 5.5 years among the subgroups treated with simvastatin, the benefit of simvastatin in survival increased when a longer life expectancy was assumed for all survivors at the end of the trial.

The number of hospitalizations, including cardiovascular procedures such as coronary artery bypass graft (CABG) and percutaneous transluminal coronary angioplasty (PTCA), is in Table 4 . Simvastatin reduced the number of hospitalizations during the trial in all subgroups by 23 to $40 \%$. Reductions were the greatest for the diabetic group, with 393 and 472 fewer hospitalizations per 1000 patients for the clinical history and ADA defined groups, respectively.

Table 5 shows the estimated hospital costs, intervention costs and cost offsets using Swedish unit costs. When comparing the intervention costs for simvastatin with the savings in costs due to fewer hospitalizations, the per cent of intervention costs offset 
Table 4. Total number of cardiovascular hospitalizations and number of cardiovascular hospitalizations per 1000 patients for subgroups defined according to clinical history and ADA criteria for diabetes (with $95 \%$ Bootstrap CI for the difference per 1000 patients between simvastatin and placebo)

\begin{tabular}{|c|c|c|c|c|c|c|c|c|}
\hline & \multicolumn{3}{|c|}{ Simvastatin } & \multicolumn{3}{|l|}{ Placebo } & \multicolumn{2}{|c|}{$\begin{array}{l}\text { Difference } \\
\text { (Simvastatin - Placebo) }\end{array}$} \\
\hline & Patients & $\begin{array}{l}\text { Number } \\
\text { of hospitali- } \\
\text { zations }\end{array}$ & $\begin{array}{l}\text { Hospitali- } \\
\text { zations } \\
\text { per } 1000 \\
\text { patients }\end{array}$ & Patients & $\begin{array}{l}\text { Number } \\
\text { of hospitali- } \\
\text { zations }\end{array}$ & $\begin{array}{l}\text { Hospitali- } \\
\text { zations } \\
\text { per } 1000 \\
\text { patients }\end{array}$ & $\begin{array}{l}\text { Hospitali- } \\
\text { zations } \\
\text { per } 1000 \\
\text { patients }\end{array}$ & $95 \% \mathrm{CI}$ \\
\hline \multicolumn{9}{|l|}{ Clinical History } \\
\hline \multicolumn{9}{|l|}{ ADA Criteria } \\
\hline NFG & 1606 & 1012 & 630 & 1631 & 1329 & 814 & -185 & $(-288,-84)$ \\
\hline IFG & 343 & 199 & 580 & 335 & 277 & 827 & -247 & $(-466,-53)$ \\
\hline Diabetic & 251 & 177 & 705 & 232 & 273 & 1177 & -472 & $(-786,-132)$ \\
\hline
\end{tabular}

Table 5. Hospital costs, prescription cost, cost offset and total costs with $95 \%$ Bootstrap CI for net cost using Swedish unit costs (in SEK) among subgroups defined according to clinical history and ADA criteria for diabetes

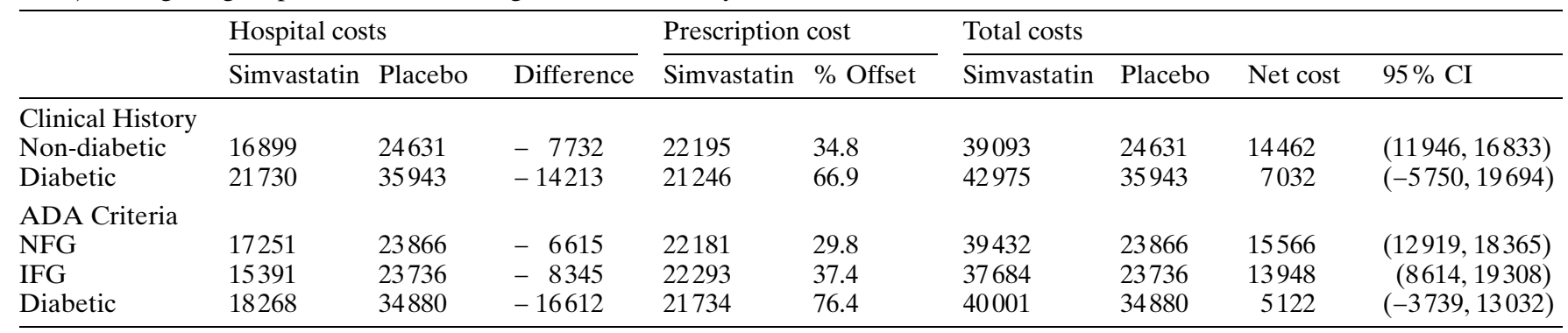

was highest in the diabetes groups $(67 \%$ and $76 \%$ cost-offset for classification based on clinical history and ADA, respectively).

Table 6 shows the cost-effectiveness ratio for Sweden and other European countries using both criteria for diabetes. All cost-effectiveness ratios are expressed in national currencies as well as Euros (ECU), converted at current exchange rates to allow comparison. Estimates of cost per life-year gained were favourable for simvastatin in all the evaluated countries. In Sweden, estimates ranged from 1554 ECU for the diabetic subgroup (based on clinical history) to $7345 \mathrm{ECU}$ for the NFG subgroup (based on ADA criteria). Because of the substantial cost offsets for the diabetes subgroup, the resulting estimates for cost per life-year gained were lower for the diabetic subgroups than for the non-diabetic subgroups. These results hold regardless of which criteria was used to classify patients according to their diabetic status. The estimated cost-effectiveness of simvastatin in the IFG group was lower than that for the NFG and diabetic subgroups.

In the other evaluated countries, intervention with simvastatin showed a favourable cost-effectiveness ratio independent of differences in local health care unit costs. In three countries (Norway, France and Belgium) simvastatin therapy in diabetic patients was cost saving. As the same utilization and survival estimates were used across all of the evaluated countries, remaining differences in estimates of cost per life-years gained were due to variations in the relative cost of hospitalizations and simvastatin across the countries.

When subgroup analyses are undertaken, the uncertainty in estimates is typically increased due to the smaller effective sample sizes. To show the magnitude of the uncertainty in the estimates of cost-effectiveness, two types of analyses are presented. The first analysis is based on the variability of bootstrap replicates and the resulting $95 \%$ bootstrap confidence intervals for the different sub-groups using Swedish cost data (Figs. 1, 2). The figures show the greater concentration of bootstrap replicates for the non-diabetic, NFG and IFG subgroups (Figs. $1 \mathrm{~A}, 2$ A, 2B) relative to the diabetic subgroups (Figs. 1B, 2 C). Consequently, the $95 \%$ confidence intervals are narrower for these subgroups and are contained within the upper right-hand quadrant (where incremental costs and benefits are positive). For the diabetic subgroups, the spread of the bootstrap replicates indicate uncertainty associated with the direction of both the incremental cost and the estimates of life-years saved (see also $95 \%$ confidence intervals in Tables 3 and 5). The resulting $95 \%$ confidence intervals for the incre- 


\section{A. Non-diabetic subgroup}

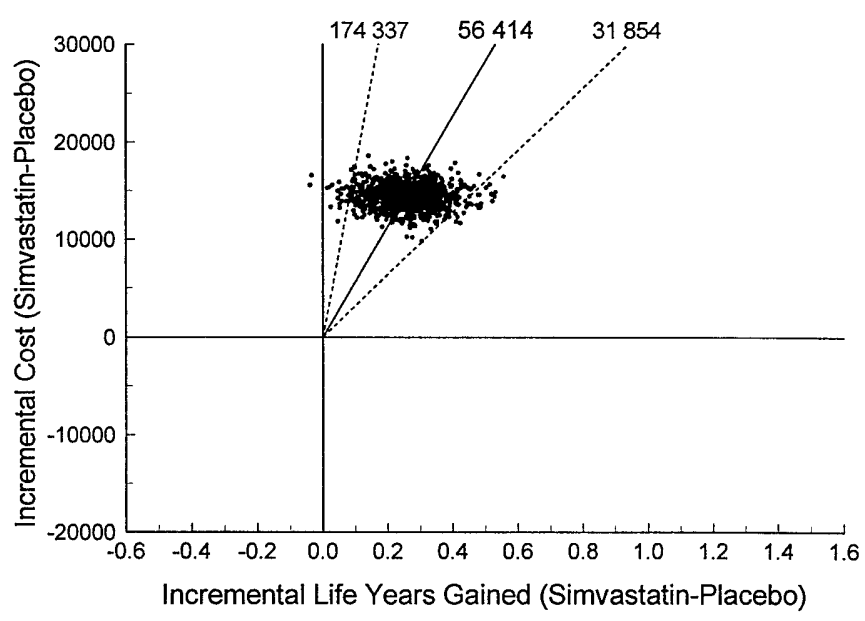

B. Diabetic subgroup

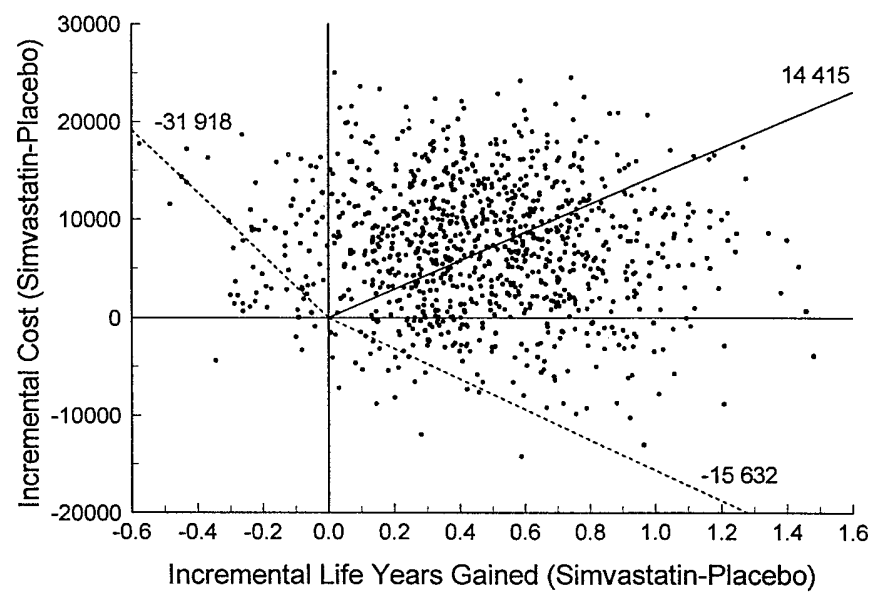

Fig.1A, B. Scatterplot of 1000 bootstrap replicates for incremental cost and life-years gained according to clinical history classification of diabetes with cost-effectiveness ratio (incremental cost per life-year gained) estimate (solid line) and $95 \%$ bootstrap CI (dashed lines containing $95 \%$ of the bootstrap replicates). (Costs in Swedish Crowns)

mental cost-effectiveness ratio are wide in order to contain $95 \%$ of the bootstrap replicates, with limits extending from the upper left-hand quadrant (with increased cost and decreased benefit associated with simvastatin) to the lower right-hand quadrant (with decreased cost and increased benefit). Only the lower left-hand quadrant (with decreased cost and decreased benefit) is excluded.

The second approach to assessing uncertainty is based on the estimated probability the cost-effectiveness ratio falls below a given threshold used for establishing a cost-effective therapy. In Sweden, a threshold value of 200000 SEK per-life year gained is often used to establish cost-effectiveness for prevention. At this threshold, there is a high probability that in-

\section{A. NFG subgroup}

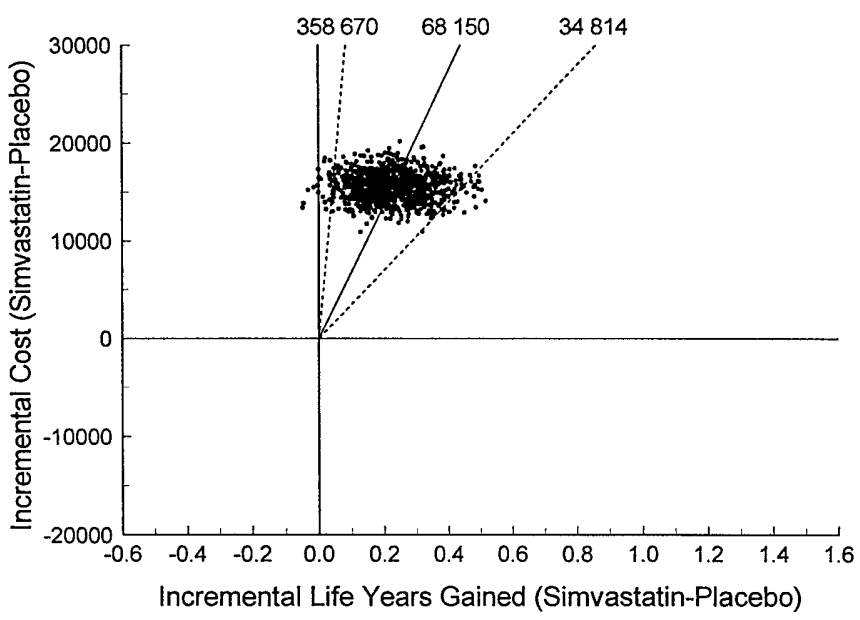

\section{B. IFG subgroup}

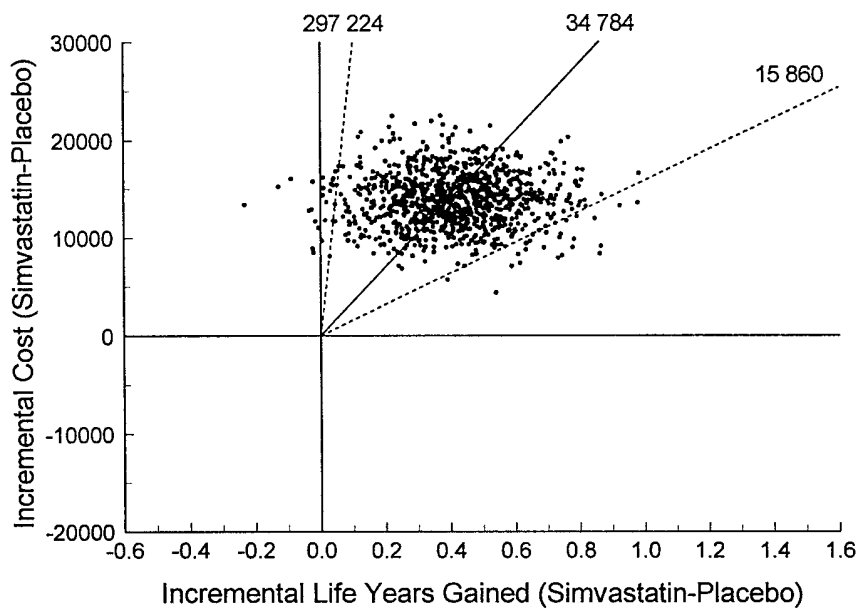

C. Diabetic subgroup

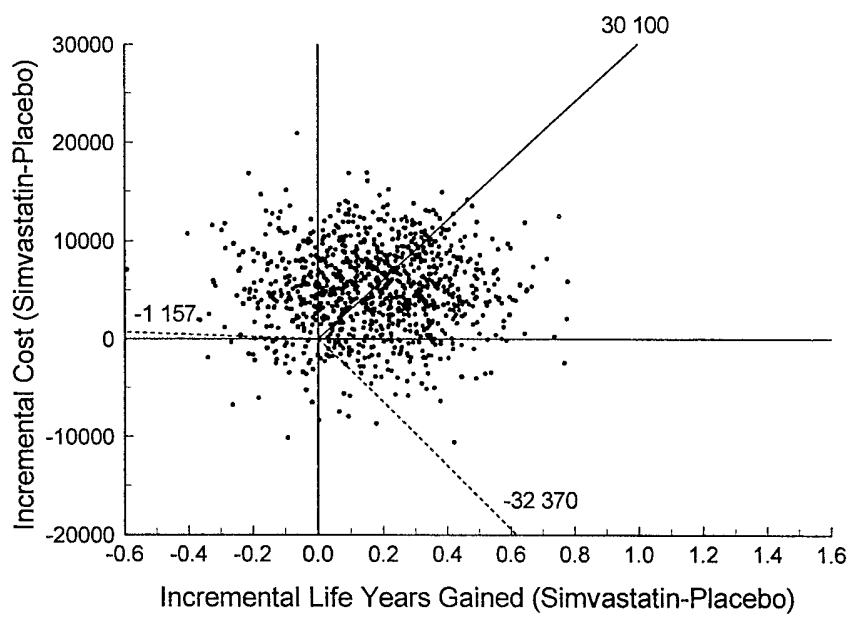

Fig. 2 A-C. Scatterplot of 1000 bootstrap replicates for incremental cost and life-years gained according to ADA criteria for diabetes with cost-effectiveness ratio (incremental cost per life-year gained) estimate (solid line) and $95 \%$ bootstrap CI (dashed lines containing $95 \%$ of the bootstrap replicates). (Costs in Swedish Crowns). 
Table 6. Cost per life year gained estimates by country for all patients combined, clinical history and ADA criteria for diabetes

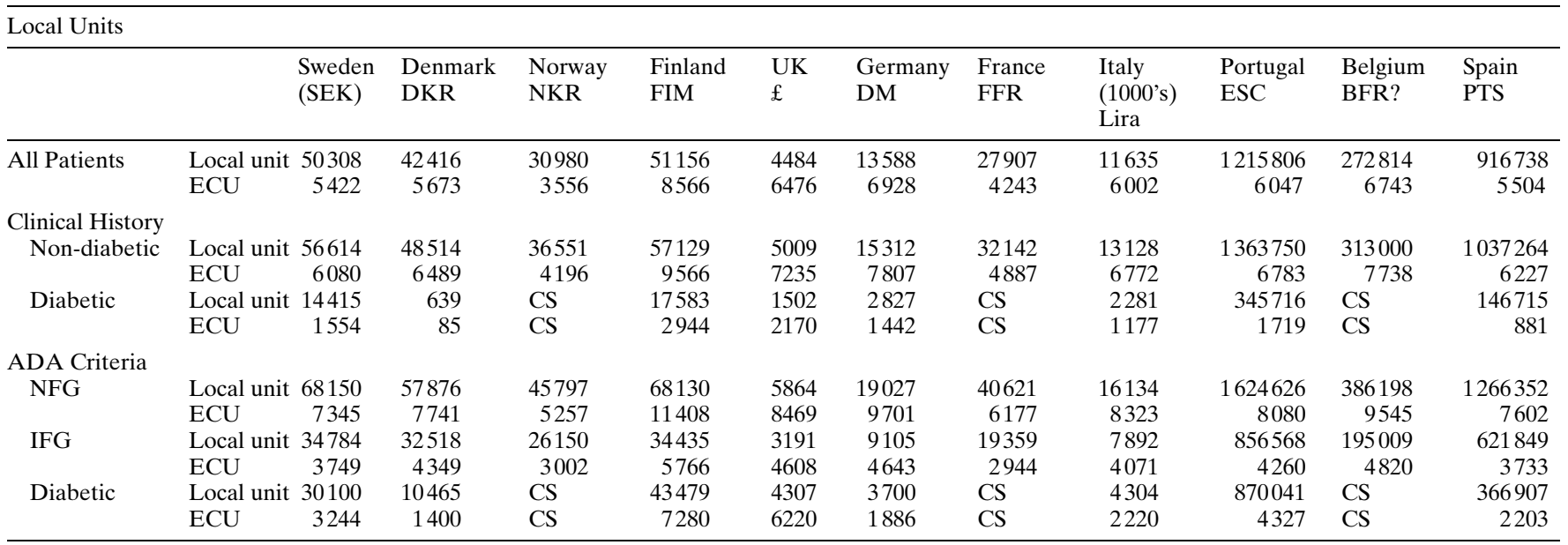

$\mathrm{CS}=$ Cost saving

Table 7. Estimated probability the cost effectiveness ratio (CER) falls below a defined threshold (in Swedish Crowns) for cost-effectiveness for subgroups defined according to clinical history and ADA criteria for diabetes

\begin{tabular}{llll}
\hline & \multicolumn{2}{l}{ CER Threshold } \\
\cline { 2 - 4 } & 100000 SEK & 150000 SEK & 200000 SEK \\
\hline Clinical History & & 0.962 & 0.983 \\
$\quad$ Non-diabetic & 0.896 & 0.897 & 0.902 \\
$\quad$ Diabetic & 0.883 & & \\
ADA Criteria & & 0.898 & 0.941 \\
NFG & 0.763 & 0.961 & 0.970 \\
IFG & 0.933 & 0.736 & 0.747 \\
Diabetic & 0.703 & & \\
\hline
\end{tabular}

tervention with simvastatin would be cost-effective, with estimates ranging from 0.75 to 0.98 for the various subgroups (Table 7). Even if a threshold of 100000 SEK per-life year gained is used, the probabilities remain high that the simvastatin therapy will be considered cost-effective. The smaller probability associated with the diabetic subgroup (ADA classification) is due to the greater uncertainty in the magnitude of the life expectancy gains resulting from the smaller sample size.

\section{Discussion}

In $4 \mathrm{~S}$, patients with diabetes had a lower probability of survival than non-diabetic patients regardless of the classification used for diabetes. In addition to the 202 patients diagnosed as diabetic by clinical history, 281 additional subjects met $\mathrm{ADA}$ criteria by FG equal or greater than $7.0 \mathrm{mmol} / \mathrm{l}$. When comparing the two classifications used, the probability of survival in the placebo group was lower in the diabetic group based on clinical history alone than in the extended group of diabetic patients with FG equal or greater than $7.0 \mathrm{mmol} / \mathrm{l}$. The difference in survival, however, was negligible between the two groups of diabetic patients treated with simvastatin. Thus, when using the ADA classification criteria for diabetes, the gain in life expectancy from treatment was smaller than that based on clinical history. It is difficult to explain this difference, which very well could be due to chance because of the small sample and great variation observed.

For the placebo patients who met the criteria for IFG with FG between $6.0 \mathrm{mmol} / \mathrm{l}$ and $7.0 \mathrm{mmol} / \mathrm{l}$, hospitalization rates, costs and estimates of survival fell between the diabetic and the non-diabetic group. For the simvastatin treated patients, however, this group showed a lower rate of hospitalization and total cost and a higher probability of survival than NFG patients, which was contrary to expectations. Again, this could very well be explained by the small sample size for the subgroup.

Diabetic patients were hospitalized for cardiovascular reasons more frequently than non-diabetic patients. Patients receiving simvastatin were hospitalized less frequently regardless of diabetic status, with greater reduction for the diabetic than non-diabetic populations. Consequently, the absolute reduction in the number of hospitalizations, and thus the cost offsets, were greater with intervention among diabetic than non-diabetic patients. This effect was accentuated with the ADA criteria for diabetes and the difference between IFG and diabetic patients was greater than between NFG and IFG patients. Since the intervention cost were very similar among subgroups over the follow up period, differences in hospital cost offsets resulted in a much lower net cost for the diabetic group.

Despite slightly lower gains in life expectancy in the diabetic group classified by ADA, the cost effectiveness results for diabetic subjects was consistently lower than for non-diabetic people independent of the 
classification scheme used. If we used the original definition of diabetes, the cost-effectiveness in the diabetic population would be much better than in the non-diabetic population. With the ADA classification, the gain in life expectancy was slightly lower in the diabetic group, but cost-effectiveness was still better in the diabetic population due to the substantially lower net cost. The cost-effectiveness for the diabetic sub-population was better than for the non-diabetic population, by either criterion, but the results were also more variable due to the smaller sample size. The confidence interval was rather narrow for the non-diabetic population. For the non-diabetic population the cost-effectiveness ratio was similar to what had been estimated for the whole $4 \mathrm{~S}$ population [12].

We assumed that among patients with heart disease, those with diabetes have shorter life expectancy than those who are non-diabetic. The estimates were uncertain, and a sensitivity analysis was done to investigate the importance of this assumption. The conclusions about the better cost-effectiveness for diabetic patients were not affected by different assumptions about survival after the end of the trial, but the absolute level of the cost per life-year gained were affected. A longer life expectancy at the end of the trial reduced the cost per life-year gained.

Estimates for cost-effectiveness based on $4 \mathrm{~S}$ resource utilization and local unit costs, were generated in 10 other European countries to evaluate the impact of variations in local hospitalization and drug costs on the results of these analyses. The interpretation of these results, however, must take into consideration that they were based on Scandinavian hospital admission data and procedure rates. It had been shown previously that the pattern of resource consumption did not differ much between the five Nordic countries participating in the study [12]. Thus we feel confident in applying unit costs in these countries to the aggregated resource consumption in the trial. For the non-Nordic countries, the validity of the results depended on the similarity of local patterns of hospital admission and procedure use to what had been observed in $4 \mathrm{~S}$. The rates of PTCAs in the countries participating in $4 \mathrm{~S}$ are similar to the European average; however, rates of CABGs in some countries are slightly higher than in Europe as a whole. These differences should be taken into consideration when interpreting these results.

The results of cost-effectiveness for all the evaluated countries were highly favourable, there were differences in the estimates of actual cost per life-years gained. Given that the same survival and utilization data from the trial were used across all these countries, differences in costs per life-years gained, after converting national currencies to Euros, were due to differences in unit costs for hospitalizations relative to simvastatin. Since international trade reduces the variation in international drug prices, variations in the estimates of cost per life-years gained were largely driven by differences in hospitalization costs. In general we expected richer countries to have a lower cost- effectiveness ratio, since wages, the major part of hospital costs, are higher in relation to the price of the drug. In countries with a lower GDP per capita, hospital costs are relatively lower.

The cost-effectiveness ratios can be compared with other interventions aimed at reducing longterm complications due to diabetes. For subjects with Type I (insulin-dependent) diabetes, studied within the Diabetes Control and Complications Trial, an incremental cost per life-year gained of US\$ 28661 ( 229000 SEK; US\$ 1 8 SEK) was reported [22]. For Type II (non-insulin-dependent) diabetes, the incremental cost per quality adjusted life-year gained was estimated to be US\$16 $000(\sim 128.000$ SEK) [23]. Even though it is difficult to directly compare those studies with ours, the cost-effectiveness of lipid lowering as secondary prevention appeared to be more cost-effective than treatment of Type II diabetes with the goal of normoglycaemia.

In this analysis the cost and differential benefit of treatment with simvastatin was limited to the trial period. Gains in life expectancy beyond the trial period were due only to the greater survival probability at 5.5 years in the trial. While it is clearly not recommended to stop treatment with simvastatin after 5.5 years, we chose not to make assumptions about the continuation of differential survival benefit associated with and subsequent cost of simvastatin therapy in this analysis.

These data confirm previously published data showing that in all the evaluated subgroups in $4 \mathrm{~S}$, cholesterol reduction with simvastatin was highly cost-effective. While the care of diabetic subjects in $4 \mathrm{~S}$ cost less per life-year gained than the non-diabetic patients, the cost-effectiveness of care for non-diabetic patients was still within the range generally considered to be extremely cost-effective when compared with other medical interventions. We obtained less precise results for the diabetic cohort because of its small size than for the non-diabetic group. These results did not depend on the criteria used for diabetes. When the diabetic patients were removed from the analysis, simvastatin continued to be cost-effective in patients with cardiovascular disease. Based on the results of $4 \mathrm{~S}$, cholesterol lowering with simvastatin provided good cost-effectiveness in both diabetic and non-diabetic patients with cardiovascular disease.

Acknowledgements. We are grateful to D. Gomes for help with collection of cost data for this study. 


\section{References}

1. Rubin RJ, Altman WM, Mendelson DN (1995) Health care expenditures for people with diabetes mellitus. Diabetes Spect 8: 3

2. American Diabetes Association (1987) Direct and indirect costs of diabetes in the United States in 1987. Alexandria, VA ADA

3. Ray NF, Willis S, Thamer M (1993) Direct and indirect costs of diabetes in the United States in 1992. Alexandria, VA ADA

4. Huse D M, Oster G, Killen R, Lacey M, Colditz, G (1989) The economic cost of non-insulin dependent diabetes mellitus. JAMA 262: 2708-2713

5. American Diabetes Association (1998) Economic consequences of diabetes mellitus in the U.S. in 1997. Diabetes Care 21: 296-309

6. Jönsson B (1983) Diabetes: the cost of illness and the cost of control. Acta Med Scand, 671 (Suppl):19-27

7. Henriksson F, Jönsson B (1998) Diabetes: the cost of illness in Sweden. Journal of Internal Medicine 244: 461-468

8. Herlitz J, Malmberg K, Karlsson BW, Ryden L, Hjalmarsson $\AA$ (1988) Mortality and morbidity during five-year follow-up of diabetes with myocardial infraction. Acta Med Scand 224: 31-38

9. Karlsson BW, Herlitz J, Hjalmarsson Å (1993) Prognosis of acute myocardial infarction in diabetic and non-diabetic patients. Diabet Med 10: 449-454

10. Pyorala K, Pedersen T, Kjekshus J et al. (1997) Cholesterol lowering with simvastatin improves prognosis of diabetic patients with coronary heart disease. Diabetes Care 20: 614-620

11. Haffner S, Alexander CM, Cook TJ et al. (1999) Reduced coronary events in simvastatin-treated subjects with coronary heart disease and diabetes or impaired fasting glucose: subgroup analysis in the Scandinavian Simvastatin Survival Study (4S). Arch Int Med (In press)

12. Jönsson B, Johannesson M, Kjekshus J, Olsson AG, Pedersen TR, Wedel $\mathrm{H}$ for the Scandinavian Simvastatin Survival Study Group (1996) Cost effectiveness of cholesterol low- ering: results from the Scandinavian Simvastatin Survival Study (4S). Eur Heart J 17: 1001-1007

13. Johannesson M, Jönsson B, Kjekshus J, Olsson AG, Pedersen TR, Wedel $\mathrm{H}$ for the Scandinavian Simvastatin Survival Study Group (1997) Cost effectiveness of simvastatin treatment to lower cholesterol levels in patients with coronary heart disease. N Engl J Med 336: 332-336

14. Pedersen T, Kjekshus J, Berg K et al. (1996) Cholesterol lowering and the use of healthcare resources: results of the Scandinavian Simvastatin Survival Study. Circulation. 93: 1796-1802

15. Statistics Sweden. Statistical Yearbook of Sweden 1995, 51-52 (official publication)

16. Malmberg K, Ryden L, Efendic S et al. (1995) A randomized trial of insulin-glucose infusion followed by subcutaneous insulin treatment in diabetic patients with acute myocardial infarction: effects on one year mortality(DIAGAMI study). JACC 26: 57-65

17. Olsson G, Rehnqvist N, Sjogren A, Erhardt L, Lundman T (1985): Long-term treatment with metoprolol after myocardial infarction: effect on 3-year mortality and morbidity. JACC 5: 1428-1437

18. Hedbäck B, Perk J (1987) 5-year results of a comprehensive rehabilitation programme after myocardial infarction. Eur Heart J 8: 234-242

19. Efron B, Gong G (1983) A leisurely look at the bootstrap, jackknife and cross-validation. The American Statistician. 37: $36-48$

20. Johannesson M, Meltzer D (1998) Some reflections on cost-effectiveness analysis. Health Economics 7: 1-8

21. Polsky D, Glick HA, Wilke R, Schulman K(1997) Confidence intervals for cost-effectiveness ratios: a comparison of four methods. Health Economics 6: 243-252

22. DCCT Research Group (1996) Lifetime benefits and costs of intensive therapy as practiced in the diabetes control and complications trial. JAMA 276: 1409-1415

23. Eastman RC, Javitt JC, Herman WH et al. (1997) Model of complications of NIDDM. II. Analysis of the health benefits and cost-effectiveness of treating NIDDM with the goal of normoglycemia. Diabetes Care 20: 735-744 